\title{
КРИТЕРИИ И ПОКАЗАТЕЛИ ОЦЕНКИ ЭФФЕКТИВНОСТИ ИННОВАЦИОННОГО ПРЕДПРИЯТИЯ В УСЛОВИЯХ ИМПОРТОЗАМЕЩЕНИЯ (НА ПРИМЕРЕ ПРЕДПРИЯТИЙ МЕДИЦИНСКОЙ ПРОМЫШЛЕННОСТИ)
}

\section{CRITERIA AND INDICATORS FOR EVALUATING THE EFFECTIVENESS OF AN INNOVATIVE ENTERPRISE IN THE CONTEXT OF IMPORT SUBSTITUTION (ON THE EXAMPLE OF MEDICAL INDUSTRY ENTERPRISES)}

\section{A. Ovchinnikov}

Summary. The purpose of the study is to develop a system of criteria and performance indicators for an innovative medical industry enterprise operating in the context of import substitution. Among the objectives of the study: to clarify the priority sectors of import substitution, to determine the features of innovative activities of medical industry enterprises, to develop a system of criteria and indicators of the effectiveness of these enterprises. General and private scientific methods are used as research methods: analysis, comparison, and abstraction. The results obtained in the study-the proposed criteria and indicators of the effectiveness of an innovative medical industry enterprise operating in the context of import substitution-can be used both at the micro level (in the activities of such enterprises) and at the level of state management of innovative development of individual sectors of the economy in the context of import substitution. Conclusion: improving the management efficiency of innovative enterprises in the context of import substitution requires increased attention to all components of the mechanisms and management systems formed in such enterprises. The efficiency assessment allows us to answer the question about the economic effectiveness of resources aimed at innovative development.

Keywords: innovative enterprise, performance criteria, performance indicators, medical industry.

\author{
Овчинников Алексей Павлович \\ К.э.н., дочент, Российский университет \\ транспорта (МИИТ) \\ alexovchinnikov@mail.ru
}

Аннотация. Цель исследования состоит в разработке системы критериев и показателей эффективности инновационного предприятия медицинской промышленности, функционирующего в условиях импортозамещения. В числе задач исследования: уточнить приоритетные отрасли импортозамещения, определить особенности инновационной деятельности предприятий медицинской промышленности, разработать систему критериев и показателей эффективности функционирования данных предприятий. В качестве методов исследования используются обще- и частнонаучные методы: анализ, сравнение, абстракция. Полученные в исследовании результаты - предложенные критерии и показатели эффективности инновационного предприятия медицинской промышленности, функционирующего в условиях импортозамещения,- могут использоваться как на микроуровне (в деятельности таких предприятий), так и на уровне государственного управления инновационным развитием отдельных отраслей экономики в условиях импортозамещения. В качестве основного вывода исследования отмечается, что повышение эффективности управления инновационными предприятиями в условиях импортозамещения требует повышенного внимания ко всем составляющим формируемых в таких предприятиях механизмов и систем управления. Оценка эффективности позволяет дать ответ на вопрос 0 экономической результативности направленных на инновационное развитие ресурсов.

Ключевые слова: инновационное предприятие, критерии эффективности, показатели эффективности, медицинская промышленность.

поддержки предприятий в рамках политики импортозамещения; разработка государственных программ поддержки инновационных предприятий в условиях импортозамещения; выделение государством необходимого объема ресурсов для осуществления данной политики. На микроуровне формируются системы управления инновационными предприятиями, адапти- 
Таблица 1. Комплекс критериев и показателей оценки эффективности предприятий медицинской промышленности в условиях осуществления

\begin{tabular}{|c|c|}
\hline Критерии эффективности & Показатели эффективности \\
\hline $\begin{array}{l}\text { Эффективность инновационной } \\
\text { деятельности }\end{array}$ & $\begin{array}{l}\text { Группа показателей, характеризующих степень инновационности деятельности } \\
\text { предприятия медицинской промышленности: коэффициент инновационности, } \\
\text { коэффициент Тобина, сроки окупаемости исследований (индекс возврата } \\
\text { инвестиций в научные исследования и разработки). } \\
\text { Группа показателей, характеризующих научно-техническую результативность } \\
\text { инновационной деятельности предприятия медицинской промышленности: } \\
\text { количество инновационных идей, выдвинутых сотрудниками предприятия } \\
\text { за период; количество зарегистрированных прав на объекты интеллектуальной } \\
\text { собственности; количество публикаций; количество внедренных в производство } \\
\text { инновационных технологий. }\end{array}$ \\
\hline $\begin{array}{l}\text { Эффективность основной деятельности } \\
\text { (во взаимосвязи с долгосрочными } \\
\text { государственными приоритетами развития } \\
\text { медицинской промышленности) }\end{array}$ & $\begin{array}{l}\text { Группа показателей, характеризующих вклад в реализацию государственной } \\
\text { программы развития медицинской промышленности: количество созданных } \\
\text { высокопроизводительных рабочих мест; индекс производительности труда; доля } \\
\text { высокотехнологичной продукции в общем объеме выпускаемой продукции; доля } \\
\text { наукоемкой продукции в общем объеме выпускаемой продукции; темпы прироста } \\
\text { объема экспорта медицинских изделий. } \\
\text { Группа показателей производственного эффекта от инновационной деятельности: } \\
\text { экономия материальных ресурсов, экономия затрат, рост производительности } \\
\text { труда, прирост объемов производства. } \\
\text { Группа показателей, характеризующих влияние инновационной деятельности } \\
\text { на финансовую эффективность предприятия медицинской промышленности: } \\
\text { прирост выручки, прирост прибыли, прирост рентабельности, сокращение сроков } \\
\text { окупаемости инвестиционных проектов. }\end{array}$ \\
\hline $\begin{array}{l}\text { Эффективность участия в стратегии } \\
\text { импортозамещения }\end{array}$ & $\begin{array}{l}\text { Изменение доли рынка предприятия в соответствующем нишевом сегменте } \\
\text { продукции медицинского назначения } \\
\text { Темпы прироста реализации инновационной продукции, участвующей в программе } \\
\text { импортозамещения } \\
\text { Темпы прироста экспорта продукции предприятия медицинской промышленности } \\
\text { при условии осуществления им внешнеэкономической деятельности } \\
\text { Доля рынка предприятия по направлениям экспорта продукции } \\
\text { Уровень конкурентоспособности продукции (интегральный показатель, } \\
\text { рассчитываемый на основе сравнительного анализа ряда частных показателей) } \\
\text { предприятия медицинской промышленности } \\
\text { Эффективность использования государственной поддержки на осуществление } \\
\text { политики импортозамещения }\end{array}$ \\
\hline
\end{tabular}

Источник: разработано автором

рованные к задачам политике импортозамещения. Один из элементов таких систем на микроуровне подсистема оценки эффективности.

Оценка эффективности субъектов экономической деятельности в целом и инновационных предприятий в частности во многом определяется отраслевой спецификой. К одной из приоритетных отраслей для осуществления политики импортозамещения органами государственной власти отнесена медицинская промышленность [8]. Вопрос формирования отдельных элементов управления инновационными предприятиями медицинской промышленности в условиях импортозамещения не остался без внимания исследователей $[1,5,6,7]$. В числе аспектов деятельности предприятий медицинской промышленности исследователями также рассматривался вопрос эффективности их функционирования [2-4].
Формирование критериев и показателей оценки эффективности предприятий медицинской промышленности в условиях осуществления стратегии импортозамещения требует учета следующих сторон решения данной научной задачи:

1. Требуется учитывать особенности функционирования инновационных предприятий. В данной части следует принимать во внимание процессный, многоэтапный, многосубъектный характер деятельности таких предприятий.

2. Следует учитывать отраслевую специфику функционирования предприятий медицинской промышленности. В том числе следует иметь ввиду характер выпускаемой продукции и удовлетворяемых данной продукцией потребностей, а также ряд других отраслевых особенностей. В данной части следует также принимать во внимание существующие го- 
сударственные программы развития предприятий медицинской промышленности и разработанные в их рамках критерии и показатели эффективности.

3. Следует учитывать задачи осуществления политики импортозамещения. Полагаем, в условиях импортозамещения требуется решить следующие задачи: повысить конкурентоспособность внутренних производителей в сравнении с зарубежными поставщиками без ущерба для внутренних потребностей в продукции предприятий медицинской промышленности; укрепить конкурентоспособность отечественных производителей на внешних рынках; создать условия для минимального влияния конкурентных условий в случае «ослабления» существующего благоприятного режима импортозамещения для внутренних производителей.

С учетом перечисленных требований можно предложить следующий комплекс критериев и показате- лей оценки эффективности предприятий медицинской промышленности в условиях осуществления (таблица).

Подводя итог следует отметить, что повышение эффективности управления инновационными предприятиями в условиях импортозамещения требует повышенного внимания ко всем составляющим формируемых в таких предприятиях механизмов и систем управления. Оценка эффективности позволяет дать ответ на вопрос о экономической результативности направленных на инновационное развитие ресурсов. Приведенный комплекс критериев и показателей, во-первых, не является исчерпывающим и может быть дополнен другими показателями в соответствии с конкретными управленческими потребностями. Во-вторых, из него при необходимости могут исключаться отдельные показатели в случае отсутствия у субъектов оценки соответствующих ресурсов для проведения масштабных исследований эффективности.

\section{ЛИТЕРАТУРА}

1. Арестов А.А. Проблемы и перспективы импортозамещения в российской экономике на примере медицинской отрасли // Universum: медицина и фармакология. 2020. № 1 (65). С. 9-11.

2. Герцик Ю.Г., Герцик Г.Я. К вопросу разработки критериев эффективности и рекомендаций по формированию государственных программ развития медицинской промышленности РФ // Экономика и предпринимательство. 2015. № 2 (55). С. 128-133.

3. Герцик Ю.Г., Герцик Г.Я. Повышение эффективности производства в России инновационных медицинских изделий с учетом разработанной классификации предприятий медицинской промышленности // Инновации. 2014. № 11 (193). С. 64-73.

4. Герцик Ю.Г., Иванова Г.Е. Экономическая эффективность и критерии конкурентоспособности учреждений здравоохранения и предприятий медицинской промышленности РФ // Обязательное медицинское страхование в Российской Федерации. 2014. № 6. С. 70-73.

5. Еменекова А.А., Демьянец А.В., Хачин С.В. Импортозамещение в отраслях экономики (на примере медицинской промышленности) // Производственный менеджмент: теория, методология, практика. 2016. № 6. С. 185-189.

6. Кудрявцева Т.Ю., Схведиани А.Е., Козлова Е.А. Коммерциализация инновационных диагностических приборов медицинского назначения в условиях реализации стратегии импортозамещения в России // Глобальный научный потенциал. 2016. № 9 (66). С. 44-51.

7. Новикова Е.В., Евсеев А.В., Попов Ю.С., Довлетли К.О. Развитие фармацевтической и медицинской промышленности в РФ после санкций ЕС и США // Вестник Смоленской государственной медицинской академии. 2019. Т. 18. № 2. С. 209-215.

8. Чиновники определили приоритетные отрасли для импортозамещения. PБK. URL: https://www.rbc.ru/economics/20/01/2015/54be941b9a79473ac2a4 4d29\#: : text=Приоритетные\%20отрасли\%20для\%20импортозамещения.\%200борудование, промышленность\%2С\%20судостроительное\%200борудование\%20(в\%20части (дата обращения: 19.05.2021).

(c) Овчинников Алексей Павлович (alexovchinnikov@mail.ru ).

Журнал «Современная наука: актуальные проблемы теории и практики» 